\title{
The Way of Expanding Technology Acceptance-Open Innovation Dynamics
}

\author{
Ma. Nanette Casquejo ${ }^{1}{ }^{(}$, Celbert Himang ${ }^{2}{ }^{-}$, Lanndon Ocampo ${ }^{2,3, *}$, Rosein Ancheta Jr. ${ }^{2}$, \\ Melanie Himang ${ }^{4}$ and Miriam Bongo ${ }^{3}$ \\ 1 College of Computer Studies, University of the Immaculate Conception, Davao City 8000, Philippines; \\ ma.casquejo@gmail.com \\ 2 Graduate School, Cebu Technological University, Cebu City 6000, Philippines; cmhimang@gmail.com (C.H.); \\ rosein.ancheta@ctu.edu.ph (R.A.J.) \\ 3 Department of Industrial Engineering, Cebu Technological University, Cebu City 6000, Philippines; \\ miriam.bongo@yahoo.com \\ 4 College of Information and Communications Technology, Cebu Technological University, Cebu City 6000, \\ Philippines; himangmel@gmail.com \\ * Correspondence: lanndonocampo@gmail.com
}

Received: 1 September 2019; Accepted: 9 January 2020; Published: 2 February 2020

\begin{abstract}
To promote efficient use of electrical energy, technology-based solutions, along with their corresponding user acceptance assessments, have been seen to facilitate goal fulfillment concerning desired functionality and expected benefits, in an open innovation fashion. This paper simultaneously develops an electrical energy consumption monitoring system (EECMS) device that shall monitor and control the use of energy in real-time and assesses its acceptability to users according to the extended technology acceptance model (TAM) approach. This proposed EECMS device is tested in an academic institution in the Philippines, and it is found that the device can function as desired as well as render a significant favor from its users according to additional key constructs. As such, future developments of the device are encouraged to enhance key constructs identified as suitable for future adoption.
\end{abstract}

Keywords: energy consumption; energy monitoring; technology development; technology acceptance evaluation; extended TAM

\section{Introduction}

The use of energy has become an integral part of growing an economy [1]. As increasingly new energy sources are explored along with the open innovation of energy industry technology, macroeconomic growth is understood to rise [2]. With the favorable shift of economic status, the process of urbanization, standards of living, and even climate change perspectives have prompted the variation in energy consumption [3]. This premise holds, especially in the case of developing countries where rural household energy consumption takes up a significant portion of total energy consumption. Aside from rural households, school buildings are also found to be responsible for a significant proportion of total energy consumption, which, in turn, translates into a considerable amount of carbon dioxide emissions [4,5]. Recognizing the harmful effects of carbon dioxide, being the primary cause of global warming and constituting $80 \%$ of the total greenhouse gas emissions [6,7], not only to the environment but also to human health [8], the need to mitigate emissions by effective energy consumption strategies becomes an urgent concern [9].

Several efforts have been exerted to manage energy consumption both globally and locally. Many countries are attempting to reduce energy consumption in the building sector, particularly schools, by pursuing an eco-school plan for educational facilities with the aid of programs on the Zero Energy 
Building (ZEB) and Zero Energy House (ZEH) [10-14]. For instance, Korea recommends instilling institutional improvements through the use of renewable energy to reduce total energy consumption and to develop relevant technologies at the same time [15]. In another case, improving housing design is also perceived to produce effective strategies for energy consumption, which further brings the necessity to better understand the use of energy, including the ownership of electrical appliances and user behavior [16]. Nevertheless, the improvement of energy consumption through various means has to be well-established since technical progress in this area can lead to a rebound effect [17]. That is, new demands for energy partially offset the savings in consumption, which thus leads to increased energy consumption [18]. In developing countries such as Thailand, an Energy Efficiency Plan (EEP) was formulated in 2015 as a master plan which sets a target of a 30\% reduction in the energy consumption of the country [19]. Further, performance indices for industry sectors such as Baseline Energy Consumption (BEC) and Specific Energy Consumption Index (SEC) are carefully studied to support the regulation of energy efficiency-related activities that the government has promulgated. A similar policy is pushed forward in the Philippines under the Philippine Energy Plan, whose goal is to create energy efficiency a way of life for the citizens [20]. Under this nationwide plan, energy efficiency and conservation are maintained as be one of the social pillars to be achieved in 2030 .

These efforts converge on the idea of engaging and empowering consumers to manage their resources consciously through increased consumption visibility and accurate measurement [21]. Currently, the improvement of energy consumption is focused on the development of a technology-based solution [22-25]. Such technologies make use of the Internet of Things (IoT) as one of its earliest significant applications for energy optimization owing to its capability of controlling and monitoring energy consumption. As a digitalization tool, IoT allows for real-time and seamless integration of worldwide network infrastructure, enabling communication among devices and assets via interoperable protocols possible [26-29]. Furthermore, it is imperative to note that the development of an electricity consumption monitoring system is not a new phenomenon. In fact, a plethora of technology-based advanced monitoring systems throughout the United States and many other developed countries was implemented two decades ago [30,31]. Furthermore, investigations of factors affecting users' acceptance of the technology-based energy management innovation have also been widely discussed separately [32-35].

The objective of this paper, therefore, is to develop a technology for energy consumption management and investigate the factors that affect users' acceptance via an extended TAM model incorporating economic, social, and environmental aspects of technology adoption. While prior studies in the literature focus on separately developing technology for energy consumption and assessing its user acceptance, none has taken into account simultaneously these two measures despite the essential relation between these constructs. Furthermore, as a technology for adoption is developed, its associated impact on its potential users, as described by the user acceptance model, becomes an imperative action. The need to describe the acceptance of technology becomes apparent, mainly for users who have limited resources to allocate for further innovative advancement. The rest of the paper discusses the foundation of technology development, specifically in energy consumption sector as well as the technology acceptance model and its extensions. Then, the research issues found in the literature are explored together with the formulation of hypotheses among user acceptance constructs. The succeeding sections then present the case study and the key results obtained from the case. Then, a conclusion is drawn to provide insights on the generated results.

\section{Background of The Study and Hypotheses Development}

\subsection{Energy Consumption Management}

There are different opportunities for reducing electricity consumption in buildings, but identifying and quantifying them is often regarded as time-consuming or expensive, particularly in single-family households [36]. The lack of information about their actual energy consumption makes it difficult 
for users who are willing to save energy to make the necessary action in effectively reducing energy usage [37]. Typically, feedback on energy use is reported on a monthly utility bill, which does not allow sufficient guidance for individual energy-saving actions. There are, however, several residential electricity sensors available in the market which can aid in the monitoring of energy consumption, thereby, suggesting an effort to save energy. Table 1 lists off-the-shelf products that depict energy consumption in near real-time conditions. However, neither option can track the changes in energy (electric) usage of the individual appliances as well as the aggregated load over time, not to mention its relatively expensive acquisition cost.

Table 1. Commercially available residential electricity meters by type.

\begin{tabular}{cc}
\hline Type of Meter & Meter Brand/Model \\
\hline Whole-house & $\begin{array}{c}\text { The Energy Detective (TED) } \\
\text { Power Cost MonitorTM }\end{array}$ \\
\hline Plug-load meters & $\begin{array}{c}\text { Powerkuff Monitor } \\
\text { WattsUp? PRO }\end{array}$ \\
\hline Packaged solutions & Kill-a-watt \\
& AlertMe \\
\hline
\end{tabular}

As a supplement to meter technologies, other smart power outlets, as in Table 2, provide remote access to readings via wireless communications, thus enabling users to access the data on their mobile phone or through the web. One limitation, though, is on the number of devices that can be directly attached to the outlet of such systems, e.g., Kill-a-Watt and Click, and its relatively high cost [24].

Table 2. Energy management systems.

\begin{tabular}{clc}
\hline Type & \multicolumn{1}{c}{ Features } & Reference \\
\hline PowerPedia & $\begin{array}{l}\text { A mobile application that allows users to assess and } \\
\text { determine the electricity consumption of individual } \\
\text { devices as well as the energy efficiency of the } \\
\text { appliances. It also enables users to identify and } \\
\text { compare their consumption with that of others. }\end{array}$ & [38] \\
\hline Building Energy & $\begin{array}{l}\text { Integrates users' responses in building controlling } \\
\text { and monitoring remotely. }\end{array}$ & [39,40] \\
\hline Hanagement System & $\begin{array}{l}\text { Home Energy Management System (HEMS) is a } \\
\text { product utilizing the smart grid. It provides real-time } \\
\text { information of supplied electricity price, the } \\
\text { Management System }\end{array}$ & electricity consumption of each household, and the \\
& $\begin{array}{l}\text { electricity rate of each household. It also has a } \\
\text { function that notifies the consumers when they have } \\
\text { already exceeded the limit preset by the user through } \\
\end{array}$ & a warning sound or automatically turning off the \\
& power to prevent unnecessary power use. & \\
\hline
\end{tabular}

The use of IoT as a support to provide energy management systems has proved to be useful in sensing technology and energy infrastructure, allowing information to be processed and displayed in a fast and accurate way [41]. Note that IoT-related technologies have also proved to have an impact on information and communications technology (ICT), particularly in academic institutions [42,43]. Presently, IoT enables the interconnection between things or devices, including, but not limited to, electronic devices, machines, smartphones, and the internet, by using identification codes that work uniquely to allow communications among devices [44,45]. This technology also supports other advances such as cyber-physical systems to maintain interoperability among connected users, therefore, permitting the exchange of information between devices [46,47]. Some typical applications of IoT 
devices in the field include that of radio-frequency identification (RFID), connectivity/communication electronics and software, global positioning systems (GPS), context-aware networks, smartphones (e.g., Wi-Fi, Bluetooth, and cellular networks), sensors, actuators, and algorithms, among others [26,47-49]. With IoT, users experience significant benefits mainly in terms of shortened production cycles, incorporation of customer needs in real-time, and automatic order and delivery schemes, to name a few [50]. That is, a form of digitalization that revolutionizes the way organizations operate within industrial value chains.

Additionally, in the energy sector, [51] reported that electricity sensors offer support in saving energy for residential sectors. Note that the use of sensors and microcontrollers in the area of energy monitoring showed varied results. For example, [52] created a power monitoring smart meter using Arduino, which has a built-in LCD that displays the power consumption with the cost of electricity. They recommend using wireless technology to make consumption data accessible through the internet. Since the Arduino board has no built-in Ethernet port, a base shield should be provided. In another work, [53] developed a wireless sensor network system using both Arduino and Raspberry Pi. With the addition of another equipment, the cost of developing the design was relatively higher than that of [52]; nevertheless, the scalability of the sensor node connections and memory of the design developed was favorable. A comprehensive study conducted by [51] examined different commercially available smart meters type (i.e., whole-house meter, plug load meters, package solutions). In this work, it was revealed that whole-house meter only reports coarse real-power readings that cannot differentiate appliances with similar wattage. Correspondingly, while plug-load meters are designed to measure a single device, establishing the trend of power consumption takes a considerable amount of time. Lastly, the package solutions referred to as smart home solutions, typically leverage multiple metering technologies to provide an all-encompassing solution but with a higher price. Similarly, [24] also developed a smartphone application integrated into a smart meter infrastructure. It allows the user to explore not only energy consumption but also compare it with peers. The only drawback of using this application lies in its need to have a smart meter infrastructure.

Several scholars claimed that providing a technology-based solution increases awareness and understanding of electricity consumption [23,30,54-56]. As such, [22] confirmed that after the installation of real-time aggregate feedback in college dormitories, a $55 \%$ reduction of electricity consumption was evident. Consequently, a multitude of empirical studies has examined the extent to which feedback can reduce energy consumption, whether delivered via a monitoring system or other means [30].

\subsection{Users' Acceptance of A Technology Supporting Energy Efficiency Management}

The adoption of technology relies on the influencing factors associated with the acceptance and the direction of such a technology. In the literature, several theoretical models aim to explain consumers' acceptance of, in particular, information technology including the Theory of Reasoned Action (TRA) (see for instance [57,58]), Theory of Planned Behavior (TPB) (see for instance [59,60]), Unified Theory of Acceptance and Use of Technology (UTAUT) (see for instance [61,62]) and Technology Acceptance Model (TAM). Among these theoretical models, TAM is considered to be one of the most accepted models for understanding the usage and adoption of technology. This model is firstly described by [63] under psychometric research of which variances related to users' behavioral intention and information technology adoption, in specific, are discussed. Note that TAM is also one of the most potent extensions of TRA [63], which replaces several attitude measures of TRA with two other technology acceptance measures: perceived ease of use (PEU) and perceived usefulness (PU) of technology. Furthermore, TAM also predicts a user's acceptance of IT and its usage on the job [64] while explaining the determinants of user acceptance of a wide range of end-user computing technologies [63]. The core component common to all modifications of TAM consists of three constructs: perceived usefulness (PU), perceived ease of use (PEU), and behavior intention (BI) $[65,66]$. 
A further extension of TAM (i.e., e-TAM) is developed to explain software and IT product behavior perspective $[23,34,35,67]$. This model is recently implemented by [23] by proposing a consumer acceptance model for the Home Energy Management System (HEMS). In this work, consumer acceptance intention based on two factors influencing consumer acceptance-belief in attitude and belief norm-are investigated. Belief in attitude has positive (i.e., suitability, economic benefits, usefulness, ease of use) and negative (i.e., security risk and costs) factors that influence the use of HEMS. Furthermore, belief about norms is divided into social influence and responsibility. These variables are independent of each other; hence, there is no mediating relationship between these variables.

The consumer acceptance model for HEMS previously developed by [23] has been recently referred to by [35] with a few changes. Here, they found that economic benefit, social contribution, and environmental responsibility has a positive influence on the usefulness of HEMS. Furthermore, it is found that the introduction of innovative IT products poses problems to consumers who are quite pessimistic and uncomfortable with the idea of accessing or using them. Similarly, limited time for additional attempts to process the knowledge about the new approaches and technologies also appears to be a concern [68]. To overcome this negative outlook, the benefits of a new product are proposed to be fully recognized in terms of usefulness. Such an action can be pioneered by early adopters since they are already optimistic about new technology and are willing to take the risk at the same time [69]. Clearly, evaluating technology for potential adoption may not only focus on the technical and functional aspects of product development but also on the essentials of conducting user acceptance testing to assess the users' behavior intention to adopt the technology.

\subsection{Research Issues and Hypotheses}

The extended TAM introduces external variables such as economic benefit, social contribution, environmental responsibility, and innovativeness [35] in addition to the original TAM constructs, perceived ease of use, perceived usefulness, and behavior intention. Economic benefits refer to the monetary incentives that the consumer gains when using a technology. On the other hand, a social contribution is characterized by having a positive view of services and products in terms of social impact. Environmental responsibility is defined as an energy-saving behavior, which is a decisive factor in the environment, and innovativeness pertains to the attitude of an individual who wants to acquire and use technology more quickly than others. Recall that the key constructs of the original TAM are perceived usefulness, perceived ease of use technology, and behavioral intention. Perceived usefulness (PU) explains the extent to which a person believes that using the system shall enhance job performance. Perceived ease of use (PEU) denotes the belief that using the system is effortless. Then, behavior intention refers to users' perception of the intention to use the system.

These constructs are significant in understanding users' adoption of a new technology $[63,70]$. Also, the relationship between perceived ease of use and user behavior is widely regarded in the literature, whereas usefulness showed a significant influence on behavioral intention [71]. Several research works have also presented an explicit discussion on the relationship among these constructs under various domains (see [66,72-74]).

The development of a technology that can support the effective management of energy consumption and the implementation of user acceptance has not yet been carried out in the literature despite its potential individual contribution. Thus, as a contribution to the body of knowledge, particularly in open innovation domain, this paper aims to develop a novel device that can monitor and measure the energy consumption in a building via the use of sensors and at the same time, validate the corresponding hypotheses related to the constructs of extended TAM. Note that the integration of additional key constructs to the traditional TAM proves to be of high regard, particularly for users whose decision-making process for technology adoption also considers the areas of economic benefits, social contribution, environmental sustainability, and innovativeness. This direction encourages an open innovation platform, which is crucial in the promotion of sustainability in today's fourth industrial revolution [75]. As the technology adoption decision becomes more complex as it proceeds, 
it only fits to comprehensively consider other key aspects that decision-makers also factor in to ensure the success of the adoption.

Hypotheses

As an essential part of collaborative consumption, the economic benefit is believed to represent a specific instrumental value, along with convenience, which users can obtain from using a technology [76]. Such economic benefit is thus classified as extrinsic motivation and an antecedent of perceived usefulness. A mediating role has been found between perceived usefulness and economic benefit. That is, when consumers achieve an increased economic benefit through savings (e.g., discounts and free strategy), their usage habits and loyalty are enhanced. Thus, organizations are encouraged to provide more value and benefits in services (e.g., technology) offered to enhance the level of perceived usefulness, which, in turn, translates into loyalty [77]. Some economic benefits may come in forms of incentives such as convenience, information, entertainment, and interactivity [78].

While technology is developed for the specific purpose of advancement, users tend to find products useful when no detrimental results are evident in the environment due to its future use [79]. It is essential to consider that perceived usefulness has a considerable positive impact on their attitude towards sustainable use. In other words, increasing consumer awareness of sustainability issues of certain products aids in the continuation of its use due to the favorable perception attached to it $[80,81]$. Notably, consumers are more drawn to support products that are more environmentally and socially responsible [79]. At a broader scope, [26] found that people tend to favor services, particularly restaurants, which adopted sustainable practices leading towards a responsible economic, social, and environmental use of resources. That is, as a set of elements including, but not limited to, energy efficiency, waste reduction, and safety are satisfactorily utilized in the delivery of service, a corresponding sense of usefulness becomes apparent to users. As a result, service providers aimed at adopting strategies that encompass environmental, social, and economic sustainability by considering the classical variables of the theory of planned behavior. Specifically, sustainable practices generate positive impacts on all three dimensions of sustainability from the environment to social and economic aspects [79]. In another case of agricultural advancement, [82] noted that through modern, innovative production techniques which are viewed as essential for ensuring economic profitability and sustainability among young farmers, its eventual adoption becomes a major decision for farmers to make. In the case of the energy sector, [35] also emphasizes that savings in electricity consumption dramatically affect the perceived usefulness of the system, which leads consumers to continue using such a system. Thus, hypotheses regarding the relationship of economic benefits, environmental responsibility, social contribution to perceived usefulness, respectively are presented as follows:

Hypothesis 1 (H1). Economic benefits have a positive impact on perceived usefulness.

Hypothesis 2 (H2). Environmental responsibility has a positive impact on perceived usefulness.

Hypothesis 3 (H3). Social contribution has a positive impact on perceived usefulness.

To increase the level of perceived usefulness, and even perceived ease of use, a significant positive role is played by innovativeness [83-85] in such a way that it engages in the process of adoption and use of new products [86]. Innovativeness, defined as the willingness of an individual to try out any new technologies made available in the market [35], influences users to exhibit a strong motivation to use new technology provided that the perceived ease of use is readily evident. The degree of innovativeness substantially improves the explanatory power of the TAM approach as it does not only directly and positively influence users' future intentions to use technology-based products but also relates to its corresponding perceived ease of use. Furthermore, it has been found that the role of innovativeness entices consumers to have more intrinsic utilities for utilizing such a system [87]. It is, furthermore, imperative to note that the innovativeness serves as the central element in the concept 
of diffusion of innovation theory, which mainly relates to the tendency of adopting innovations [88]. Thus, the following hypothesis can be made:

Hypothesis 4 (H4). Innovativeness has a positive impact on perceived usefulness.

A widely accepted notion presents that for users to be more motivated to adopt a technology, they should perceive such technology not to be complicated for them to find it more useful and easier to use [86,88]. In a particular case of the probable continuance intention of using e-government, both perceived usefulness and perceived ease of use have been theorized as primary constructs to determine the adoption of e-government [89]. Apparently, a significant relationship is found between these two constructs, and the continuance intention of using e-government only revealed that the correlation between perceived usefulness and technology involved a higher magnitude of relationship over perceived ease of use [90]. Such a relationship highlights the premise that when the technology is considered useful, not to mention its ability to provide an added feature to users, then a tendency for users to continue using the technology becomes evident. As such, the following hypothesis is formulated:

Hypothesis 5 (H5). Perceived ease of use has a positive impact on perceived usefulness.

On the relationship of perceived ease of use and perceived usefulness to behavior intention, a positive correlation is explicitly found in the potential adoption of a learning resource [91,92]. Note that an interesting finding between these constructs relationship exposes that the use of auxiliary support systems in the learning environment becomes relatively harder for people with increasing age [92]. Thus, strategic learning processes and modules are suggested to maintain the relationship between perceived ease of use and perceived usefulness and behavior intention, even in the inevitable aging of users. In a rather similar context regarding mobile environment knowledge management, perceived ease of use and perceived usefulness is also found to be positively influenced by behavior intention [78,93]. Furthermore, users tend to adopt certain behaviors based on how well a product helps them perform an activity [26,63], often suggesting how usefulness serves as an important determinant of any system use. In other words, perceived usefulness creates the image of product-related attributes, which is designed to influence and eventually serve consumers. In line with this, the following hypotheses on the impact of behavioral intention to perceived ease of use and perceived usefulness are introduced:

Hypothesis 6 (H6). Perceived ease of use has a positive impact on behavior intention.

Hypothesis 7 (H7). Perceived usefulness has a positive impact on behavior intention.

\section{Methodology}

\subsection{Case Study Background}

In the Philippines, a developing country with minimal resources in a topographical region, the need to efficiently make use of energy is an urgent concern, particularly for government policymakers. In fact, an energy efficiency roadmap and a National Energy Efficiency and Conversation Program (NEECP) vision were crafted in 2009 to promote a more energy-efficiency country across all sectors, including the industry, transportation, commercial, and residential. Recognizing that both residential and industrial sectors of the country significantly contributes to the increase of the overall energy consumption, it is only imperative to regulate the use of energy in such sectors [20]. As an illustration of the proposed theoretical framework on TAM and empirical testing of a technology that aims to wirelessly measure and transmit real-time electricity consumption data of individual and aggregated 
electricity loads, a case study was conducted at an academic institution located in Davao City, a huge city in the far south of the Philippines. This institution houses pre-school to junior high school programs with rooms ventilated by air-conditioning units for approximately eight hours every school day.

\subsection{Research Participants}

A total of 94 respondents $(n=94)$ were included in this study ( 5 members of the board, 2 administrators, 6 non-teaching staff, 10 teaching staffs, 41 students, 30 parents). As decision-makers of the academic institution under study, these respondents are deemed appropriate to evaluate the proposed EECMS device introduced for energy efficiency, given that they too can influence the eventual implementation of the technology should it be found sufficiently favorable.

\subsection{Instruments}

Two primary instruments are used in this work with the purpose (1) to develop the proposed EECMS device prototype and (2) to assess the user acceptability of the device in the context of an academic institution. First, it involves the use of sensors, current transformers, clamp ammeter, and a database to serve as storage of electrical readings obtained during each run. The next instrument is a 5-point survey questionnaire which aims to assess the user acceptance of the proposed EECMS device following the extended TAM approach $[35,63]$. Here, the demographics of the subjects and their evaluations in terms of technology acceptability were gathered.

\subsection{Design}

The proposed EECMS device is developed with aims to measure and transmit real-time electrical consumption data in the academic institution with the use of sensors. The checking for the precision and accuracy of the proposed EECMS device is done through a series of pilot runs and re-calibrations on the installation of the sensors, transformers, and clamp ammeter. A detailed procedure of setting up the proposed EECMS device is as follows:

(1) The sensor was clipped on either side of the live wire of an extension cord or directly on the supply side of the circuit breaker panel to avoid cancellation of current that would result in a zero measurement.

(2) The collection of data for the individual load was done for at least $30 \mathrm{~min}$ or until a pattern of load measurement was observed. A commercial clamp ammeter was also clipped on one side of the live wire to get an independent measure of the current flowing in the wire. Furthermore, readings obtained from the commercial clamp ammeter shall be compared to that of the proposed EECMS device for revalidation purposes. In testing the precision of the proposed EECMS device, only the measured current was considered since the clamp ammeter can only display current and not power consumption.

(3) To check the accuracy of the proposed EECMS device, the sensor was clipped on one wire of the supply side of the panel. Taking note of the time it was clipped, an initial reading of the electric meter was made and recorded. Another reading obtained after two hours was noted to get the total kilowatt-hour consumption. These readings are then compared to the reading results taken from the electric meter and the output generated by the EECMS to check whether discrepancies of output were evident.

(4) The proposed EECMS device was installed for approximately two weeks, while the reading of the electric meter was done every morning to test the accuracy of the device output. Note that the device was tested using different electrical loads with the following duration of each load type (see Table 3). 
Table 3. The total testing time for each electrical load.

\begin{tabular}{ccc}
\hline Load Description & EMS Device & Clamp Ammeter \\
\hline Appliances & 360 min per appliance & 6 min per appliance \\
Circuit breaker A & 960 min per circuit breaker & 6 min per circuit breaker \\
Circuit breaker B & 960 min per circuit breaker & 6 min per circuit breaker \\
Circuit breaker C & 600 min per circuit breaker & 6 min per circuit breaker \\
Main circuit breaker & 4320 min & 6 min per circuit breaker \\
\hline
\end{tabular}

Once the proposed EECMS device was established and is ready for use, it was then deployed in the academic institution. The proposed EECMS device was left to run for a week in the academic institution while the subjects were instructed to function as they usually would. Then, the survey questionnaire was handed over the subjects to accomplish through an electronic survey form.

Results from the survey questionnaire deployed were run through partial least squares (PLS) structural equation modeling (SEM) analyses to further evaluate the interrelationships among constructs pertaining the user acceptability of the proposed device. PLS-SEM is deemed suitable for use in this work since the goal is directed toward distinguishing the interrelationships among extended TAM constructs concerning technology adoption. Correspondingly, PLS path modeling can be able to generate reliable results given the small sample size as compared to a complex model $[94,95]$.

The study utilized Cronbach's alpha to test the internal consistency of the scale. According to $[96,97]$, a coefficient scale above 0.70 presents a valid measurement of the construct. The composite reliability test was also performed with a threshold value of 0.60 [98]; then, the average variance extracted was also calculated with a cut-off value of 0.50 [97]. The last two tests indicate the convergent and discriminant validity of the data. The factor analysis testing with a minimum value of over 0.50 [99] indicates which of the predictor variable items have the most substantial influence in the overall factors of the model. The model was assessed using three criteria: (1) path coefficients $(\beta),(2)$ path significant ( $p$-value), and (3) variance explain $\left(R^{2}\right)$. The validation of the structural model was achieved using SmartPLS 3.2.4 The design model follows the guidelines provided in the SmartPLS Manual [100].

In testing of the hypotheses, a $t$-statistic of greater than 1.96 and a $p$-value of less than 0.01 were used to determine acceptance or rejection. Furthermore, a 95\% confidence interval was adopted for all tests. The equivalent qualitative and quantitative scoring shows the interpretation of the acceptability of the indicators of each construct.

\section{Results and Discussion}

This section presents the key results obtained from the empirical case study conducted in an academic institution with the following general focus: first, to measure and transmit real-time electricity consumption data using sensors through a proposed EECMS device, second, to assess the user acceptability of the technology using the extended TAM approach, and lastly, to evaluate the interrelationships among constructs in the user acceptability extended TAM approach.

\subsection{The Proposed EECMS Device}

In the development of the proposed EECMS device, the following technical requirements and functionality are established to ensure that the technology performs as desired. Note that the proposed EECMS device is designed to be a low cost, user-friendly electrical energy consumption monitoring system composed of hardware and software which can measure, transmit, record, and store real-time electricity consumption via the internet using Google spreadsheet as its data backend. The device also utilizes a non-invasive current transformer and microcontroller to automate the measurement and collection of individual and aggregate electricity consumption up to a maximum current rating of 100A.

Hardware. Shown in Table 4 is the summary of the system's hardware components and its corresponding specifications. While there are some current transformer (CT) sensors available in the 
market, most of the sensors require tedious invasive and semi-invasive installation. To overcome these drawbacks, the proposed EECMS device uses an SCT 013000 current transformer that can accurately measure electric current up to a maximum of $100 \mathrm{~A}$ by merely clipping it directly on the insulated wire. Moreover, the sensor is also compatible with particle photon microcontroller used to automate the collection and transmission of electric current data measured by the sensor. The Particle Photon is built-in with a powerful STM32 ARM Cortex M3 microcontroller and a Broadcom BCM43362 Wi-Fi chip for fast and convenient connection to the internet. It has an available 18 mixed GPIO pins and a web-based IDE that resembles Arduino IDE to provide easy interfacing of hardware and software components. The photon is primarily designed for use in conjunction with the Internet of Things (IoT) and has free access to Particle Cloud for designing and creating connected devices, including over-the-air firmware updates, an easily operated REST API, and firmware development using the web and local IDEs.

Table 4. The proposed EECMS device's hardware components and its specifications.

\begin{tabular}{|c|c|}
\hline Components & Specifications \\
\hline Laptop Computer & $\begin{array}{l}\text { Operating System: Mac OS Sierra version } 10.6 .12 \text { or later } \\
\text { Processor: } 1.6 \mathrm{GHz} \text { intel core i5 } \\
\text { Memory: 4GB, } 1600 \mathrm{Mhz} \\
\text { Hard Drive: } 250 \mathrm{~GB} \\
\text { Networking Hardware: } 10 / 100 / 1000 \text { Ethernet adapter }\end{array}$ \\
\hline Smartphone & $\begin{array}{l}\text { Platform: IOS } \\
\text { 1.3GHz dual-core Apple A7 (64-bit ARMv8) processor, 1GB of RAM } \\
\text { Platform: Android 5.1 } \\
\text { RAM. 1.5GB. }\end{array}$ \\
\hline Photon particle microcontroller & $\begin{array}{l}\text { Particle PØ Wi-Fi module } \\
\text { Broadcom BCM43362 Wi-Fi chip } \\
\text { 802.11b/g/n Wi-Fi } \\
\text { STM32F205RGY6 120Mhz ARM Cortex M3 } \\
\text { 1MB flash, 128KB RAM } \\
\text { On-board RGB status LED (ext. drive provided) } \\
\text { 18 Mixed-signal GPIO and advanced peripherals }\end{array}$ \\
\hline SCT 013000 current sensor & $\begin{array}{l}\text { Input Current: } 0 \sim 100 \mathrm{~A} \mathrm{AC} \\
\text { Output Mode: } 0 \sim 50 \mathrm{~mA} \\
\text { Non-linearity: } \pm 3 \% \\
\text { Turn Ratio: } 100 \mathrm{~A}: 0.05 \mathrm{~A} \\
\text { Resistance Grade: Grade B } \\
\text { Work Temperature: }-25^{\circ} \mathrm{C}-+70^{\circ} \mathrm{C}\end{array}$ \\
\hline Extension cord & $\begin{array}{l}\# 12 \text { Stranded copper wire } \\
\text { 3-gang outlet }\end{array}$ \\
\hline WI-FI & $\begin{array}{l}\text { Globe/Smart Broadband } \\
\text { Mobile data hotspot }\end{array}$ \\
\hline
\end{tabular}

In terms of hardware design, the proposed EECMS devices use a fritzing software application (see Figure 1) with a current transformer sensor connected to the board through an audio jack. An additional external 2 to $47 \mathrm{ohms}$ burden resistor connected in parallel is further utilized to provide a voltage proportional to the secondary current and ensure that current transformer core saturation is prevented. 


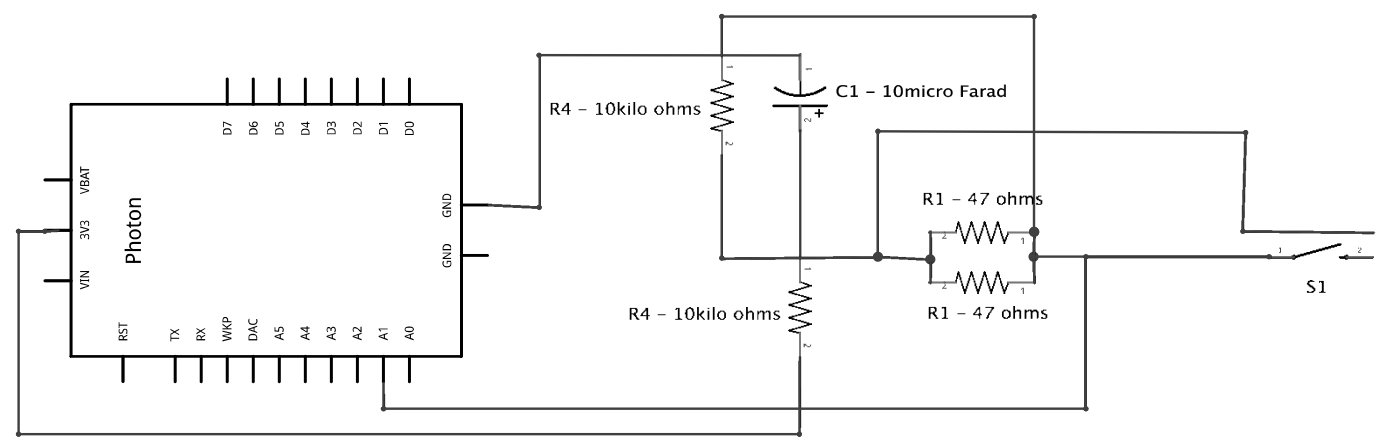

fritzing

Figure 1. Schematic diagram of the proposed EECMS device using fritzing software.

Software. In the development of the system application, particle web browser-based integrated development environment (IDE) is used to build and flash (i.e., done using the universal serial bus (USB) or over the air (OTA) through Wi-Fi) the source code to the photon microcontroller. A particle web app is an open-source mobile application used to publish the sensor data. The collected sensor data are stored in the cloud and accessed through Google sheet, particle web, and particle mobile application. Note that the operating system is Mac OS Sierra and iOS version 10.

The functionality of the proposed EECMS device. The proposed EECMS device is supported by non-functional requirements (also known as quality requirements), which impose constraints on the design or implementation such as performance requirements, precision, and accuracy. In Table 5, the results of computed descriptive statistics and confidence intervals on the measured load current of the different electrical equipment (i.e., using EECMS and using clamp ammeter) are detailed. Here, it shows that the confidence interval (CI) of the proposed EECMS device is within the range of clamp ammeter values, thereby indicating statistically non-significant results. As such, data collected using the proposed EECMS device are found to be accurate and precise, as evidenced by non-significant differences across the electrical loads used.

Table 5. Descriptive statistical representation of the electric current measured using the proposed EECMS device and commercial clamp ammeter (note: the sensor is connected to the extension cord).

\begin{tabular}{|c|c|c|c|c|c|c|c|c|c|}
\hline \multirow{3}{*}{ Load Source } & \multicolumn{4}{|c|}{$\begin{array}{c}\text { Load Current Measured Using EECMS } \\
\text { (Amperes) }\end{array}$} & \multicolumn{4}{|c|}{$\begin{array}{c}\text { Load Current Measured Using Clamp } \\
\text { Ammeter (Amperes) }\end{array}$} & \multirow{3}{*}{ Interpretation } \\
\hline & \multirow[t]{2}{*}{ Mean $(\bar{x})$} & \multirow{2}{*}{$\begin{array}{l}\text { Std. Dev } \\
(\sigma)\end{array}$} & \multicolumn{2}{|c|}{$\begin{array}{c}\text { Confidence } \\
\text { Interval (CI) }\end{array}$} & \multirow[t]{2}{*}{ Mean $(x)$} & \multirow{2}{*}{$\begin{array}{l}\text { Std. Dev. } \\
\qquad(\sigma)\end{array}$} & \multicolumn{2}{|c|}{$\begin{array}{l}\text { Confidence } \\
\text { Interval (CI) }\end{array}$} & \\
\hline & & & Lower & Upper & & & Lower & Upper & \\
\hline 1. Appliance A & 0.160 & 0.002 & 0.164 & 0.165 & 0.160 & 0.009 & 0.153 & 0.167 & Not significant \\
\hline 2. Appliance B & 0.426 & 0.522 & 0.394 & 0.458 & 0.420 & 0.468 & 0.339 & 0.501 & Not significant \\
\hline 4. Appliance D & 0.364 & 0.011 & 0.361 & 0.367 & 0.346 & 0.012 & 0.340 & 0.352 & Not significant \\
\hline 5. Appliance E & 0.294 & 0.005 & 0.293 & 0.296 & 0.285 & 0.007 & 0.281 & 0.288 & Not significant \\
\hline
\end{tabular}

As for Table 6, the detailed descriptive statistical results and the confidence interval values of the load current using both the proposed EECMS device and commercial clamp ammeter with the sensor directly connected to the circuit breaker panel board are shown. Note that the confidence interval of the proposed EECMS device and clamp ammeter shows an overlapping of values suggesting non-significance of data points. In other words, the collected data proved to be accurate and precise. 
Table 6. A descriptive statistical representation of the electric current using the proposed EECMS device and commercial clamp ammeter (note: the sensor is connected directly to the supply side of the circuit breaker in the primary circuit panel).

\begin{tabular}{|c|c|c|c|c|c|c|c|c|c|}
\hline \multirow{3}{*}{ Load Description } & \multicolumn{4}{|c|}{$\begin{array}{l}\text { Load Current in Amperes Measured } \\
\text { Using Eecms }\end{array}$} & \multicolumn{4}{|c|}{$\begin{array}{c}\text { Load Current in Amperes Measured } \\
\text { Using Clamp Ammeter }\end{array}$} & \multirow{3}{*}{ Interpretation } \\
\hline & \multirow[t]{2}{*}{$\mathbf{M}(\bar{x})$} & \multirow[t]{2}{*}{$\operatorname{SD}(\sigma)$} & \multicolumn{2}{|c|}{$\begin{array}{l}\text { Confidence } \\
\text { Interval (CI) }\end{array}$} & \multirow[t]{2}{*}{$M(\bar{x})$} & \multirow[t]{2}{*}{$\operatorname{SD}(\sigma)$} & \multicolumn{2}{|c|}{$\begin{array}{l}\text { Confidence } \\
\text { Interval (CI) }\end{array}$} & \\
\hline & & & Lower & Upper & & & Lower & Upper & \\
\hline 1. CB1 (LO 2) & 0.258 & 0.423 & 0.189 & 0.326 & 0.257 & 0.005 & 0.255 & 0.260 & Not significant \\
\hline 2. $\mathrm{CB} 2(\mathrm{LO} 3)$ & 0.701 & 0.222 & 0.658 & 0.745 & 0.700 & 0.008 & 0.694 & 0.706 & Not significant \\
\hline 3. $\mathrm{CB} 3(\mathrm{LO} 4)$ & 0.866 & 0.974 & 0.611 & 1.121 & 0.863 & 0.006 & 0.855 & 0.870 & Not significant \\
\hline 4. CB $4(\mathrm{LO} \& \mathrm{CO})$ & 0.526 & 1.054 & 0.486 & 0.566 & 0.526 & 0.005 & 0.520 & 0.532 & Not significant \\
\hline 5. CB $5(\mathrm{ACU})$ & 8.189 & 11.95 & 7.587 & 8.792 & 8.181 & 0.026 & 8.134 & 8.227 & Not significant \\
\hline 6. CB 6 (LO \& CO) & 1.099 & 1.255 & 1.023 & 1.176 & 1.091 & 0.070 & 0.944 & 1.238 & Not significant \\
\hline 7. CB 7 (ACU) & 4.090 & 7.289 & 3.841 & 4.340 & 4.091 & 0.030 & 4.019 & 4.163 & Not significant \\
\hline
\end{tabular}

Note: Circuit breaker (CB), Lighting outlet (LO), Convenience outlet (CO), Air conditioning unit (ACU).

\subsection{User Acceptance on The Proposed EECMS Device}

The proposed EECMS device is assessed in terms of user acceptance following the extended TAM which incorporates both internal, i.e., perceived ease of use (PEU), perceived usefulness (PU), behavior intention (BI), and external variables, i.e., economic benefits (EB), social contribution (SC), environmental responsibility (ER), and innovativeness (IN). The succeeding sections present in detail the perceptions of the subjects on the device according to each variable and its measurement instrument.

Perceived Ease of Use (PEU)

The user's perception in terms of the perceived ease of use of the proposed EECMS device is presented. The subjects agree and accept with a slight reservation that the installation of the system will not require much time and effort to accomplish $(\bar{x}=4.083)$, and learning how to use the proposed EECMS device is effortless and straightforward $(\bar{x}=4.021)$. Furthermore, they firmly believe that acquiring skills in using the proposed EECMS device will be relatively easy $(\bar{x}=4.223)$. However, the subjects have a neutral perception concerning the clarity of the generated report from the proposed EECMS device $(\bar{x}=3.394)$; as such, difficulty in interpreting some of the reports is often evident. The results suggest that users accept products that are perceived to be less complicated and easier to use, that is, consistent with the interpretation of [63] on the tendency of users to choose and use products that are free from complexity and trouble.

Perceived Usefulness (PU)

For the perceived usefulness (PU) construct, users strongly agree and ultimately accept that the proposed EECMS device allows online monitoring of real-time power consumption $(\bar{x}=4.234)$ and is a useful tool to understand the need for electricity consumption $(\bar{x}=4.404)$. Also, the subjects affirm that the proposed EECMS device is useful in setting power usage goals as it can report the appliance consumption while monitoring its individual and aggregated load. According to [63], perceived usefulness is the individual's belief that utilizing a new technique or technology will enhance the person's performance or routine responsibility.

Behavior Intention (BI)

On the user's perception of the intention to use the proposed EECMS device, the results suggest that users are very much willing to purchase $(\bar{x}=4.383)$ and recommend the device to others $(\bar{x}=4.372)$. Furthermore, they also anticipate added probable features of the device as a supplement to its primary function $(\bar{x}=4.351)$. 
Economic Benefits (EB)

The subjects agreed and accepted; however, with a slight reservation, that using the proposed EECMS device will benefit the academic institution economically $(\bar{x}=3.809)$. They further affirmed with the proposed EECMS device the economic value that they seek $(\bar{x}=3.683)$. The result implies that using the EECMS would help manage electricity consumption, which will, later on, translate to a reduction in electricity bills. Furthermore, [35] stated that economic benefits have a significant effect on the motivation to conserve energy hence reducing electricity consumption [23].

\section{Social Contribution (SC)}

Similar to EB, the subjects agreed and accepted with a slight reservation that spreading the use of the proposed EECMS device will lower social cost through the reduction of unnecessary power consumption and power generation charge $(\bar{x}=4.05)$. Furthermore, the subjects also attested that there should be a widespread utilization of EECMS through the formation of an economic market $(\bar{x}=3.745)$ as well as continuous research for the improvement of the device $(\bar{x}=3.702)$. In other words, the subjects favorably accept and agree that the device has a useful contribution to society. Such results are consistent with that of $[23,35]$, which showed that products and companies with high social contributions could consciously change the perception of the user towards the acceptance of the product.

\section{Environmental Responsibility (ER)}

In this construct, the subjects agreed and accepted with a slight reservation that the proposed EECMS device can promote eco-friendly energy $(\bar{x}=3.436)$, aid in the reduction of carbon dioxide emissions $(\bar{x}=3.543)$, and has a positive impact on global warming $(\bar{x}=3.649)$. These results illustrate that the device's acceptance of users is perceived to alleviate environmental problems. In this light, environmentally responsible consumers tend to conserve energy, thereby opting to choose products that perceived to be clean and green $[17,23,35]$.

Innovativeness (IN)

The subjects mostly showed a preference for the latest technology $(\bar{x}=3.840)$ and expected to be the first to acquire new devices available in the market $(\bar{x}=3.819)$. Similarly, subjects also desire to obtain up-to-date information on new technology $(\bar{x}=3.862)$ and correspondingly see improvement in their life and work through the use of such technology $(\bar{x}=4.362)$. Generally, the results indicate that users tend to accept products that are more innovative; thus, they tend to be more active in finding information, exploring new ideas, and accepting technology.

\subsection{Interrelationships Among User Acceptability Extended TAM Constructs}

This section presents two major results on the examination of the interrelationships among user acceptability in the context of extended TAM. Specifically, the structural model is presented, and analyses on the formulated hypotheses are detailed. The general structural model is utilized to simplify the interpretation and examination of the hypotheses and the bivariate relationship between the construct included in the model. As shown in Figure 2, the structural model displays the computed values of the path coefficient and the coefficient of determination $\left(r^{2}\right)$. Recall that [101] emphasized that path coefficient value determines the direct effect of a variable on another variable, and the coefficient of determination indicates the amount of variance in the construct from the path mode. All the paths showed the positive effect with the most substantial relationship between innovativeness and perceived ease of use (path weight $=0.654$ ), while the weakest is from economic benefits to perceived usefulness (path weight $=0.048$ ). Furthermore, the fit of the research model can be determined by $r^{2}$, which is the explanatory power of the model to use the technology. The $r^{2}$ of behavioral intention to use is 0.622 , which represents a stable structural model and indicates a substantial strength or effect. 


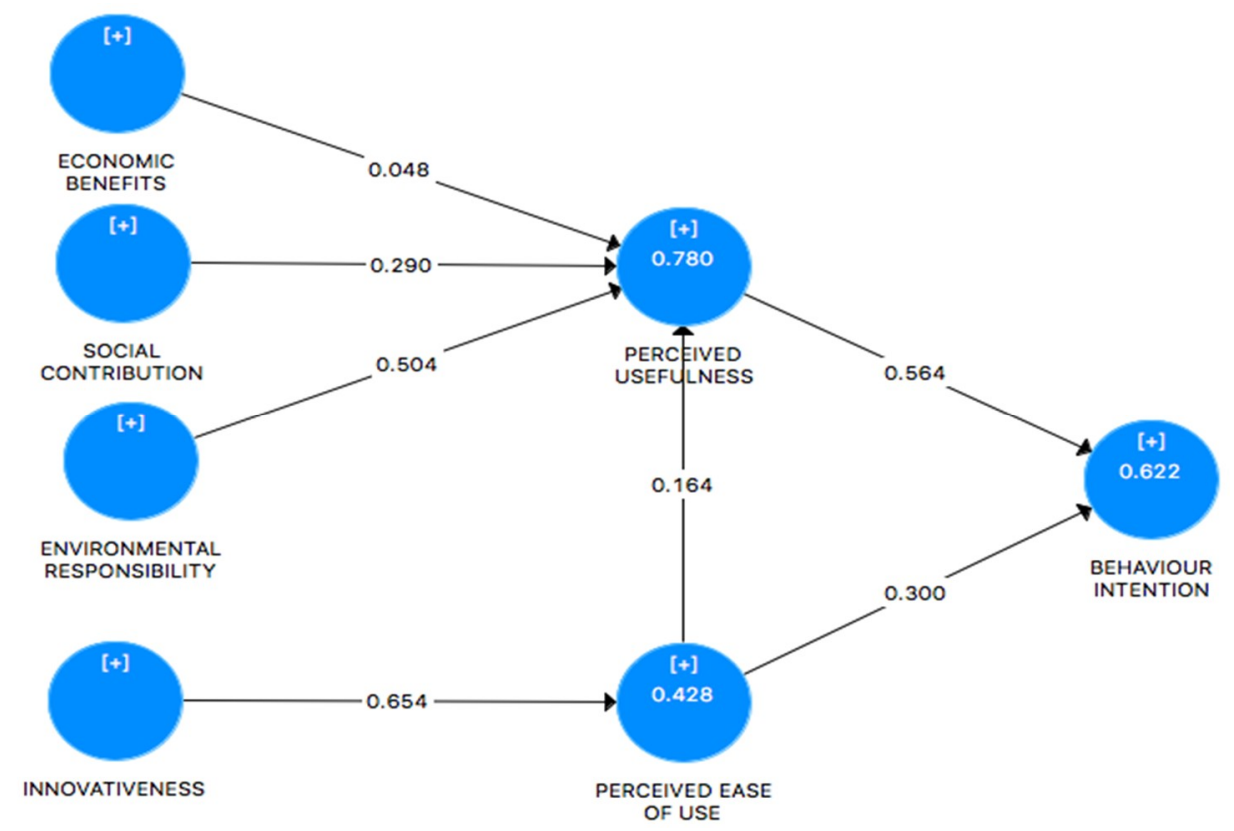

Figure 2. Structural modeling among extended TAM constructs.

Moreover, it is evident in the structural model that perceived usefulness (path coefficient $=0.564$ ) of the device has a more significant impact on the intention of using the proposed EECMS device compared to its perceived ease of use.

As emphasized by [102], a structural model is used to capture the linear regression effects of the endogenous construct upon one another, and it can specify the pattern of the relationships among the constructs at the same time [103]. In fact, this model has become an evolving area of interest to scholars due to its ability to perform direct testing of the theory concerned [104]. Recall that seven hypotheses are formulated in this paper; such hypotheses are to be confirmed via the presence of statistically significant relationships. Table 7 shows a summary of the hypotheses testing results.

Table 7. Test results of hypotheses formulated.

\begin{tabular}{lccc}
\hline \multicolumn{1}{c}{ Hypothesized Path } & $\boldsymbol{t}$-Value & $\boldsymbol{p}$-Value & Result of Hypotheses \\
\hline H1: economic benefits $\rightarrow$ perceived usefulness & 0.554 & 0.580 & Not Supported \\
H2: environmental responsibility $\rightarrow$ perceived usefulness & 7.546 & 0.000 & Supported \\
H3: social contribution $\rightarrow$ perceived usefulness & 3.794 & 0.000 & Supported \\
H4: innovativeness $\rightarrow$ perceive ease of use & 19.057 & 0.000 & Supported \\
H5: perceived ease of use $\rightarrow$ perceived usefulness & 2.841 & 0.005 & Supported \\
H6: perceived ease of use $\rightarrow$ behavioral intention & 4.468 & 0.000 & Supported \\
H7: perceived usefulness $\rightarrow$ behavior intention & 8.695 & 0.000 & Supported \\
\hline
\end{tabular}

The first hypothesis posits that there is a positive relationship between economic benefits (EB) and perceived usefulness (PU); however, this hypothesis is not statistically supported $(t$-statistic $=0.544$; $p$-value $<0.01)$. Surprisingly, this result is in contrast with [35]'s investigation, which revealed that economic benefit is the most significant predictor of the user's acceptance of the system after usefulness. Looking closely, the demographics of the subjects (i.e., $44 \%$ are grade school and high school students) implies that economic benefits derived from the use of the proposed EECMS device does not significantly motivate the intention of the subjects to use the device eventually. While in other applications such as services geared towards sustainability practices $[26,79]$ and agricultural advances [82], where there appears to be a significant relationship between economic benefits and perceived usefulness, a complete contrast is found in this work in the context of adopting an energy consumption-based technology. This can be traced back to the prior relatively reserved perception 
of users that using the proposed EECMS device will benefit the academic institution economically. Although energy consumption can be managed, the proposed EECMS device does not further suggest how users can arrive at an economical way of utilizing energy. Furthermore, an academic institution, as in the case presented, does not primarily aim to generate economic benefits from the adoption of a technology whose initial intention and design are to merely monitor and control the use of energy in real-time. Nevertheless, perceived usefulness is found to have a significant relationship with the two other sustainability constructs on the environmental aspect and social contribution.

Both Hypothesis 2 and Hypothesis 3 are supported with $t$-statistic $=7.54 ; p$-value $<0.01$, and $t$-statistic $=3.794 ; p$-value $<0.01$ for environmental responsibility (ER) and social contribution' (SC) relationship to perceived usefulness (PU), respectively. This outcome suggests that the recognition of social contribution combined with environmental responsibility increases the usefulness of the proposed EECMS device. Previous studies claimed that consumers who desire a clean and healthy environment prefer eco-friendly technology, which, in turn, they perceive as useful [35]. Similarly, [105] interpreted that consumers' actual purchasing behavior is pursued by social contributions.

As for Hypothesis 4, which predicted that innovativeness (IN) has a positive effect on perceived ease of use (PEU) of the proposed EECMS device, this hypothesis is supported ( $t$-statistic $=19.057$; $p$-value $<0.01)$ indicating that innovative products such as the proposed EECMS device are considered to be convenient and straightforward to use. In other words, users prefer the latest technology products that bring improvement in life or work. Furthermore, users tend to accept new technology that is easy to handle and maintained $[35,106]$. Such results come in parallel with the concept introduced by [88], which focused on the role of innovativeness as an intrinsic factor that influences the eventual utility of a system.

Hypothesis 5, representing the relationship between perceived ease of use (PEU) on perceived usefulness $(\mathrm{PU})$, is supported ( $t$-statistic $=2.841 ; p$-value $<0.01)$. As such, when users believe that the proposed EECMS device is easy to use, then they consider it useful. This result is consistent with that of [32,34,63]. Notably, in the case of using an e-government system [89] perceived ease of use and perceived usefulness is also deemed to have a positive, a strong relationship such that its continued use even after its initial implementation is further accepted and patronized by users due to its ease of use and usefulness in terms of record-keeping and other governance functions. Specifically, subjects of the case environment believed that the use of the proposed EECMS device does not require much time and effort to operate and that the process of learning how the device works are rather effortless and straightforward. The same contention can be directed toward the users' perceived usefulness of the proposed EECMS device in terms of monitoring the energy consumption of the academic institution. Here, users assert that they can further use the device in setting achievable goals on power usage, thereby alerting users when energy consumption becomes unusually high.

Lastly, Hypothesis 6 and 7 are also supported, of which relationships presume that both perceived ease of use $(\mathrm{PEU})(t$-statistic $=4.468 ; p$-value $<0.01)$ and perceived usefulness $(\mathrm{PU})(t$-statistic $=$ 8.695; $p$-value $<0.01$ ) positively affect behavior intention (BI) of using the proposed EECMS device. These results further suggest that users are motivated to use the system when it is perceived to be useful and easy to use. In support, [35] found that the higher the individual perceived ease of use is, the more favorable will the effect of selecting and using the product be. Furthermore, such results confirm the argument set forth by [23] that perceived usefulness dramatically affects users' intention to use the technology. Note that also in related contexts such as mobile environment knowledge management [93], both perceived usefulness and perceived ease of use have shown a positive impact on behavior intention. It is when users find that the proposed EECMS device aids in monitoring the energy consumption in the academic institution that they perceive it to be useful and easy to use at the same time. Since the case environment is an academic institution, it is imperative for users to prioritize both the ease of use and usefulness of a device to promote a high likelihood of continued use for energy consumption monitoring. 


\section{Managerial Implications}

From a managerial perspective, this study can provide an empirical illustration and evidence about the probable technology adoption of a proposed EECMS device. Developing an EECMS device to monitor and control the use of energy in real-time becomes an increasingly significant endeavor, particularly in the case of an academic institution in the Philippines where resources are considerably limited at the outset. With this work, the influencing role of economic benefits, social contribution, environmental sustainability, and innovativeness revealed that these factors are critical to the eventual implementation of such a technology, except for economic benefits. Among these factors, users are more drawn to adopt and appreciate the perceived usefulness of a technology provided that significant manifestations on the social, environmental, and innovativeness aspects are immediately apparent. Therefore, technology-based devices introduced to academic institutions are suggested to deliver the key takeaways in several forms, such as having no detrimental effects on the environment, reduction of unnecessary power consumption that is socially responsible, and elimination of technological complexity. In short, focusing on such features of an EECMS should be highly considered to ensure continuity, if not an increased manner of use of the technology. Considering that the key factors to improve perceived usefulness of proposed technology adoption are clearly identified, more interests should be expended by technology providers to anticipate a favorable adoption of technology.

Drawing from the given case condition that the users of the proposed technology are practically from the academic environment, it is imperative to note based on the results of this study that the perception toward the usefulness of the technology mainly inclines to the previous key constructs other than economic benefits. One particular advantage of monitoring and controlling energy consumption for the case academic institution lies in its efficiency of use rather than purposively reducing energy consumption. Such premise provides the grounds for users to give less concern to the economic benefits that technology can provide when used. Thus, it is useful for the technology providers to be aware that the system should be designed to work according to the goal of optimizing energy consumption, not so much so on the capability of the technology to reduce consumption. As such, the perceived usefulness of the technology is enhanced as the efficiency of the technology becomes increasingly evident.

In the context of the perceived ease of use of the technology, the results of this study revealed a significant impact it directs to the perceived usefulness and behavioral intention of the users. Following these results, as users are more able to understand the technology and how it practically works, the probability of eventual adoption based on its usefulness and the intention of the users becomes rather high. Therefore, technology developers should ascertain that the technology not only serves its purpose of monitoring and controlling energy consumption but also deems it easy to use and operate concerning the users' perspectives.

Finally, it is important to note that the potential adoption of a technology depends on the contextual description of an organization. In the case of this study, an academic institution's mission hinges primarily on the efficient use of energy, thereby creating a sort of anticipation for a technology that can well serve the organization's goal. By efficiency of energy consumption comes the user's perception of the technology's environmental, social, and innovative aspects while maintaining ease of use and usefulness. Little to no concern for the economic benefits (e.g., cost reduction) the technology can provide is taken into account as academic institutions are generally directed toward achieving efficient operations rather than economic ones.

\section{Conclusions and Future Directions}

The need to manage energy consumption, particularly in academic institutions, has become an urgent concern for policymakers to simultaneously optimize energy efficiency and maintain satisfaction among users. Such effort on energy optimization is addressed by introducing technology-based devices that can support the monitoring and control of energy consumption or by investigating the factors that influence the adoption and acceptance of technology-based devices. While such measures provide 
interestingly significant insights to the policymakers on energy optimization, no study in the literature has looked into the opportunity of combining the two methods despite the potential collective benefit it can provide in terms of technology development and user acceptance as a whole. This paper bridges the research gap on introducing a novel energy control and monitoring system device and assessing its user acceptance based on the need of the users in an academic institution in the Philippines.

Generally, the introduction of an EECMS device can perform as desired, particularly on the real-time monitoring of energy consumption. Furthermore, it has shown favorable perceptions of users in various constructs on perceived ease of use, perceived usefulness, behavior intention, economic benefits, social contribution, environmental responsibility, and innovativeness. It should be noted that while the proposed EECMS device has garnered favor among its users, policymakers delegated to promulgate technology adoption procedures in the cases environment are further encouraged to fully develop the device and ensure its full functionality over time. Similar to other forms of technology, this device may also have to undergo the normal lifecycle, which demands the utmost attention for this device to sustain popularity. Note that the results obtained from the case of this paper solely reflect that of the given environment; hence, a similar set of results may not be apparent to the general academic setting in the country. For instance, the interrelationships among user acceptability on the extended TAM constructs may be supported (i.e., economic benefits to perceived usefulness) in other cases where the perceived usefulness of technology is highly predicted by the economic benefits gained by the users who are mainly into commercialization efforts.

Furthermore, this study also takes note of the limitations of the research approach particularly on the instrument used and the design. For one, the survey questionnaire involved a 5-point scale in assessing the user acceptance of the proposed EECMS device, which follows the extended TAM approach. Limiting the subjective perception of users to numerical scales inhibits the judgment of the research subjects on the constructs considered. As a future direction, the use of linguistic scales as in fuzzy set theory can be engaged to comprehensively capture the judgment of the respondents. For another, the proposed EECMS device was initially run for approximately two weeks to monitor and control energy consumption. To ensure that no biases and irregularities relating to the environmental conditions (e.g., humidity due to time of the year) are found in the readings, it is suggested to take the energy consumption reading beyond two weeks ideally capturing a different environmental condition that may affect the heating/cooling mechanism of the appliances.

Author Contributions: Conceptualization, M.N.C.; Data curation, M.N.C.; Formal analysis, C.H.; Investigation, L.O.; Methodology, C.H.; Resources, R.A.J.; Supervision, R.A.J.; Writing—original draft, M.N.C.; Writing-review \& editing, L.O., M.H. and M.B. All authors have read and agreed to the published version of the manuscript.

Funding: This research received no external funding.

Conflicts of Interest: The authors declare no conflict of interest.

\section{References}

1. Sharma, S.S. The relationship between energy and economic growth: Empirical evidence from 66 countries. Appl. Energy 2010, 87, 3565-3574. [CrossRef]

2. Huang, Z.; Huang, L. Individual new energy consumption and economic growth in China. The North American Journal of Economics and Finance, 13 June 2019. [CrossRef]

3. Zou, B.; Luo, B. Rural household energy consumption characteristics and determinants in China. Energy 2019, 182, 814-823. [CrossRef]

4. Wang, J.C. Energy consumption in elementary and high schools in Taiwan. J. Clean. Prod. 2019, 227, 1107-1116. [CrossRef]

5. Karatasou, S.; Santamouris, M. Socio-economic status and residential energy consumption: A latent variable approach. Energy Build. 2019, 198, 100-105. [CrossRef]

6. Gustavsson, L.; Joelsson, A.; Sathre, R. Life cycle primary energy use and carbon emission of an eight-storey. Energy Build. 2010, 42, 230-242. [CrossRef] 
7. Noh, S.K.; Son, Y.H.; Bong, T.H.; Park, J.S. Characterization of $\mathrm{CO}_{2}$ emissions during construction of reservoir embankment elevation in South Korea. Int. J. Life Cycle Assess. 2014, 19, 42-51. [CrossRef]

8. Shindell, D.; Faluvegi, G.; Seltzer, K.; Shindell, C. Quantified, localized health benefits of accelerated carbon dioxide emissions reductions. Nat. Clim. Chang. 2018, 8, 291-295. [CrossRef]

9. Sugiawan, Y.; Kurniawan, R.; Managi, S. Are carbon dioxide emission reductions compatible with sustainable wellbeing? Appl. Energy 2019, 242,1-11. [CrossRef]

10. Wiik, M.K.; Fufa, S.M.; Kristjansdottir, T.; Andresen, I. Lessons learnt from embodied GHG emission calculations in zero emission buildings (ZEBs) from the Norwegian ZEB research centre. Energy Build. 2018, 165, 25-34. [CrossRef]

11. Woods, R.; Samdal, M. (Eds.) ZEB ZEB Final Report 2009-2017; SINTEF and NTNU: Oslo, Norway, 2017.

12. Moore, T. Modelling the through-life costs and benefits of detached zero (net) energy housing in Melbourne. Energy Build. 2014, 70, 463-471. [CrossRef]

13. Katafygiotou, M.C.; Serghides, D.K. Analysis of structural elements and energy consumption of school building stock in Cyprus: Energy simulations and upgrade scenarios of a typical school. Energy Build. 2014, 72, 8-16. [CrossRef]

14. Sekkia, T.; Airaksinen, M.; Saari, A. Effect of energy measures on the values of energy efficiency indicators in Finnish daycare and school buildings. Energy Build. 2017, 139, 124-132. [CrossRef]

15. Ministry of Trade, Industry and Energy (MOTIE). The Second National Master Plan for Energy. Available online: english.motie.go.kr/search/search.do?site=eng\&kwd=basic+plan\&category= c1\&reSrchFlag $=\&$ currentPage $=1 \&$ detailSearch $=\& \operatorname{srchFd}=\&$ sort $=\mathrm{d} \&$ date $=\&$ startDate $=\&$ endDate $=$ $\&$ preCondi $=\&$ rowPerPage $=10 \& \mathrm{fdTot}=\% 24$ param.fdTot\&fdTitle $=\% 24$ param.fdTitle\&fdContent $=$ $\% 24$ param.fdContent\&fdFile=\%24param.fdFile (accessed on 24 January 2020).

16. Le, V.T.; Pitts, A. A survey on electrical appliance use and energy consumption in Vietnamese households: Case study of Tuy Hoa city. Energy Build. 2019, 197, 229-241. [CrossRef]

17. Wang, Z.H.; Han, B.; Lu, M.L. Measurement of energy rebound effect in households: Evidence from residential electricity consumption in Beijing, China. Renew. Sustain. Energy Rev. 2016, 58, 852-861. [CrossRef]

18. Berkhout, P.H.G.; Muskens, J.C.; Velthuijsen, J.W. Defining the rebound effect. Energy Policy 2000, 28 , 6-7. [CrossRef]

19. Assawamartbunlue, K.; Surawattanawan, P.; Luknongbu, W. Specific energy consumption of cement in Thailand. Energy Procedia 2019, 156, 212-216. [CrossRef]

20. Department of Energy. Philippine Energy Plan 2012-2030. Policies, Regulations, Action Plans. 27 November 2013. Available online: https:/www.doe.gov.ph/pep/philippine-energy-plan-2012-2030 (accessed on 20 August 2019).

21. Anastasi, G.; Corucci, F.; Marcelloni, F. An Intelligent System for Electrical Energy Management in Buildings. In Proceedings of the 2011 11th International Conference on Intelligent Systems Design and Applications, Cordoba, Spain, 22-24 November 2011. [CrossRef]

22. Petersen, J.E.; Shunturov, V.; Janda, K.; Platt, G.; Weinberger, K. Dormitory residents reduce electricity consumption when exposed to real-time visual feedback and incentives. Int. J. Sustain. High. Educ. 2007, 8, 16-33. [CrossRef]

23. Kim, W.H.; Lee, S.; Hwang, J. Real-time energy monitoring and controlling system based on Zigbee sensor networks. Procedia Comput. Sci. 2011, 5, 794-797. [CrossRef]

24. Weiss, M.; Guinard, D. Increasing Energy Awareness through Web-Enabled Power Outlets. In Proceedings of the 9th International Conference on Mobile and Ubiquitous Multimedia, Limassol, Cyprus, 1-3 December 2010; p. 20.

25. Weiss, M.; Staake, T.; Mattern, F.; Fleisch, E. PowerPedia: Changing energy usage with the help of a community-based smartphone application. Pers. Ubiquitous Comput. 2011, 16, 655-664. [CrossRef]

26. Xu, L.D.; He, W.; Li, S. Internet of Things in Industries: A survey. IEEE Trans. Ind. Inform. 2014, 10, $2233-2243$. [CrossRef]

27. Gangwar, H.; Date, H.; Ramaswamy, R. Understanding determinants of cloud computing adoption using an integrated TAM-TOE model. J. Enterp. Inf. Manag. 2015, 28, 107-130. [CrossRef]

28. Chin, J.; Lin, S.C. A behavioral model of managerial perspectives regarding technology acceptance in building energy management systems. Sustainability 2016, 8, 641. [CrossRef] 
29. Park, E.S.; Hwang, B.; Ko, K.; Kim, D. Consumer Acceptance Analysis of the Home Energy Management System. Sustainability 2017, 9, 2351. [CrossRef]

30. Froehlich, J. Promoting Energy Efficient Behaviors in the Home through Feedback: The Role of Human-Computer Interaction. Available online: https://www.semanticscholar.org/paper/Promoting-EnergyEfficient-Behaviors-in-the-Home-\%3A-Froehlich/b353062043c1b22101e84878b6d749bf3d0fb398 (accessed on 24 January 2020).

31. Chetty, M.; Tran, D.; Grinter, R. Getting to Green: Understanding Resource Consumption in the Home. In Proceedings of the 10th International Conference on Ubiquitous Computing, Dubai, UAE, 21-22 December 2008; pp. 242-251.

32. Aslam, S.; Iqbal, Z.; Javaid, N.; Ali Khan, Z.; Aurangzeb, K.; Haider, S.I. Towards efficient energy management of smart buildings exploiting heuristic optimization with real-time and critical peak pricing schemes. Energies 2015, 10, 2065. [CrossRef]

33. Figueriredo, J.; da Costa, J.S. A SCADA system for energy management in intelligent buildings. Energy Build. 2012, 49, 85-98. [CrossRef]

34. Karlin, B.; Zinger, J.F.; Ford, R. The effects of feedback on energy conservation: A meta-analysis. Psychol. Bull. 2015, 141, 1205. [CrossRef]

35. Himang, M.M.; Mendoza, E., Jr.; Manalastas, R.; Ocampo, L.; Himang, C.M. Modeling the success of Windows Domain Network (WDN) using the DeLone \& McLean information system (IS) success model: A university case. Int. J. Sociotechnol. Knowl. Dev. 2019, 11, 30-55.

36. Berges, M.E.; Goldman, E.; Scott Matthews, H.; Soibelman, L. Enhancing electricity audits in residential buildings with nonintrusive load monitoring. J. Ind. Ecol. 2010, 14, 844-858. [CrossRef]

37. Sulaiman, M.S. Integration of Legacy Appliances into the Smart Home. Master's Thesis, Dalhousie University, Halifax, NS, Canada, 2015.

38. Ferdoush, S.; Li, X. Wireless sensor network system design using Raspberry Pi and Arduino for environmental monitoring applications. Procedia Comput. Sci. 2014, 34, 103-110. [CrossRef]

39. Hargreaves, T.; Nye, M.; Burgess, J. Making energy visible: A qualitative field study of how householders interact with feedback from smart energy monitors. Energy Policy 2010, 38, 6111-6119. [CrossRef]

40. Zuiderwjik, A.; Janssen, M.; Dwivedi, Y.K. Acceptance and use predictors of open data technologies: Drawing upon the unified theory of acceptance and use of technology. Gov. Inf. Q. 2015, 32, 429-440. [CrossRef]

41. Davis, F.D.; Bagozzi, R.P.; Warshaw, P.R. User acceptance of computer technology: A comparison of two theoretical models. Manag. Sci. 1989, 35, 982-1003. [CrossRef]

42. Au, Y.A.; Zafar, H. A Multi-Country Assessment of Mobile Payment Adoption; Working Paper Series No. 0055IS-296-2008; College of Business, University of Texas: San Antonio, TX, USA, 2008.

43. Wu, W.-W. Developing an explorative model for SaaS adoption. Expert Syst. Appl. 2011, 38, 15057-15064. [CrossRef]

44. King, W.R.; He, J. A meta-analysis of the technology acceptance model. Inf. Manag. 2006, 44, 90-103. [CrossRef]

45. Ajzen, I.; Fishbein, M. Understanding Attitudes and Predicting Social Behavior; Prentice-Hall: Englewood Cliffs, NJ, USA, 1980.

46. Mathieson, K. Predicting user intentions: Comparing the technology acceptance model with the theory of planned behavior. Inf. Syst. Res. 1991, 2, 173-191. [CrossRef]

47. Chen, L.-D.; Gillenson, D.L.; Sherrell, M. Enticing On-Line Consumers: An Extended Technology Acceptance Perspective. Inf. Manag. 2002, 39, 705-719. [CrossRef]

48. Venkatesh, V.; Davis, F.D. A theoretical extension of the technology acceptance model: Four longitudinal field studies. Manag. Sci. 2000, 46, 186-204. [CrossRef]

49. Estriegana, R.; Medina-Merodio, J.; Barchino, R. Analysis of competence acquisition in a flipped classroom approach. Comput. Appl. Eng. Educ. 2019, 27, 49-64. [CrossRef]

50. Šumak, B.; Heričko, M.; Pušnik, M. A meta-analysis of e-learning technology acceptance: The role of user types and e-learning technology types. Comput. Hum. Behav. 2011, 27, 2067-2077. [CrossRef]

51. Lemay, D.J.; Morin, M.M.; Bazelais, P.; Doleck, T. Modeling students' perceptions of simulation-based learning using the technology acceptance model. Clin. Simul. Nurs. 2018, 20, 28-37. [CrossRef] 
52. Scherer, R.; Siddiq, F.; Tondeur, J. The technology acceptance model (TAM): A meta-analytic structural equation modeling approach to explaining teachers' adoption of digital technology in education. Comput. Educ. 2019, 128, 13-35. [CrossRef]

53. Li, H.; Wen, H. How is motivation generated in collaborative consumption: Mediation effect in extrinsic and intrinsic motivation. Sustainability 2019, 11, 640. [CrossRef]

54. Alalwan, A.A.; Baabdullah, A.M.; Rana, N.P.; Tamilmani, K.; Dwidevi, Y.K. Examining adoption of mobile internet in Saudi Arabia: Extending TAM with perceived enjoyment, innovativeness and trust. Technol. Soc. 2018, 55, 100-110. [CrossRef]

55. Tsai, Y.T.; Wang, S.C.; Yan, K.Q.; Chang, C.M. Precise positioning of marketing and behavior intentions of location-based mobile commerce in the internet of things. Symmetry Plus 2017, 9, 139. [CrossRef]

56. Ma, Y.J.; Gam, H.J.; Banning, J. Perceived ease of use and usefulness of sustainability labels on apparel products: Application of the technology acceptance model. Fash. Text. 2017, 4. [CrossRef]

57. D'Souza, C.; Taghian, M.; Lamb, P. An empirical study on the influence of environmental labels on consumers. Corp. Commun. Int. J. 2006, 11, 162-173. [CrossRef]

58. Hyllegard, K.H.; Yan, R.N.; Ogle, J.P.; Lee, K.H. Socially responsible labeling: The impact of hang tags on consumers' attitudes and patronage intentions toward an apparel brand. Cloth. Text. Res. J. 2012, 30, 51-66. [CrossRef]

59. Tommasetti, A.; Singer, P.; Troisi, O.; Maione, G. Extended Theory of Planned Behavior (ETPB): Investigating customers' perception of restaurants' sustainability by testing a structural equation model. Sustainability 2018, 10, 2580. [CrossRef]

60. Michels, M.; Bonke, V.; Musshoff, O. Understanding the adoption of smartphone apps in dairy herd management. J. Dairy Sci. 2019, 102, 9422-9434. [CrossRef]

61. Lee, W.J.; Kim, T.U.; Chung, J.Y. User Acceptance of the Mobile Internet. In Proceedings of the First International Conference on Mobile Business, Athens, Greece, 8-9 July 2002.

62. Lu, J.; Yao, J.E.; Yu, C.S. Personal innovativeness, social influences, and adoption of wireless Internet services via mobile technology. J. Strateg. Inf. Syst. 2005, 14, 245-268. [CrossRef]

63. Parveen, F.; Sulaiman, A. Technology complexity, personal innovativeness and intention to use wireless internet using mobile devices in Malaysia. Int. Rev. Bus. Res. Pap. 2008, 4, 1-10.

64. Das, C. A Study on Validity of Modified Technology Acceptance Model of Mobile; RTM Nagpur University: Nagpur, India, 2011.

65. Hong, J.C.; Lin, P.H.; Hsieh, P.C. The effect of consumer innovativeness on perceived value and continuance intention to use smartwatch. Comput. Hum. Behav. 2017, 67, 264-272. [CrossRef]

66. Son, H.; Park, Y.; Kim, C.; Chou, J.S. Toward an understanding of construction professionals' acceptance of mobile computing devices in South Korea: An extension of the technology acceptance model. Autom. Constr. 2012, 28, 82-90. [CrossRef]

67. Hamid, A.A.; Razak, F.Z.A.; Bakar, A.A.; Abdullah, W.S.W. The effects of perceived usefulness and perceived ease of use on continuance intention to use e-government. Procedia Econ. Financ. 2016, 35, 644-649. [CrossRef]

68. Abbas, H.A.; Hamdy, H.I. Determinants of continuance intention factor in Kuwait communication market: Case study of Zain-Kuwait. Comput. Hum. Behav. 2015, 49, 648-657. [CrossRef]

69. Chung, H.H.; Chen, S.C.; Kuo, M.H. A study of EFL college students' acceptance of mobile learning. Procedia Soc. Behav. 2015, 176, 333-339. [CrossRef]

70. Faham, E.; Asghari, H. Determinants of behavioral intention to use e-textbooks: A study in Iran's agricultural sector. Comput. Electron. Agric. 2019, 165, 104935. [CrossRef]

71. Tang, J.T.; Chiang, C. Perceived Innovativeness, Perceived Convenience and TAM: Effects on Mobile Knowledge Management. In Proceedings of the 2009 Third International Conference on Multimedia and Ubiquitous Engineering, Qingdao, China, 4-6 June 2009; pp. 413-420.

72. Hair, J.; Anderson, R.; Tatham, R.L.; Black, W.C. Multivariate Data Analysis, 5th ed.; Prentice-Hall: Upper Saddle River, NJ, USA, 1998.

73. Loehlin, J.C. Latent Variable Models: An Introduction to Factor, Path, and Structural Analysis; Erlbaum: Hillsdale, NJ, USA, 1997.

74. Cheng, W.W.L. SEM being more effective than multiple regression in parsimonious model testing for management development research. J. Manag. Dev. 2001, 20, 650-667. [CrossRef] 
75. Brown, T.J.; Dacin, P.A. The Company and the Product: Corporate Associations and Consumer Product Responses. J. Mark. 2007, 61, 244-249.

76. Agarwal, R.; Prasad, J. A conceptual and operational definition of personal innovativeness in the domain of information technology. Inf. Syst. Res. 1988, 9, 204-215. [CrossRef]

77. Xu, L.D.; Xu, E.L.; Li, L. Industry 4.0: State of the art and future trends. Int. J. Prod. Res. 2018, 56, $2941-2962$. [CrossRef]

78. Liu, J.; Gaynor, A.T.; Chen, S.; Kang, Z.; Suresh, K.; Takezawa, A.; Cheng, L. Current and future trends in topology optimization for additive manufacturing. Struct. Multidiscip. Optim. 2018, 57, 2457-2483. [CrossRef]

79. Lu, Y. Industry 4.0: A survey on technologies, applications and open research issues. J. Ind. Inf. Integr. 2017, 6,1-10. [CrossRef]

80. Witkowski, K. Internet of things, big data, Industry 4.0-Innovative solutions in logistics and supply chains management. Procedia Eng. 2017, 182, 763-769. [CrossRef]

81. Atzori, L.; Iera, A.; Morabito, G. The internet of things: A survey. Comput. Netw. 2010, 54, $2787-2805$. [CrossRef]

82. Hermann, M.; Pentek, T.; Otto, B. Design Principles for Industrie 4. In 0 Scenarios. In Proceedings of the 2016 49th Hawaii International Conference on System Sciences (HICSS), Koloa, HI, USA, 5-8 January 2016; pp. 3928-3937.

83. Bagozzi, R.; Yi, Y. On the evaluation of structural equation models. J. Acad. Mark. Sci. 1988, 16, 74-94. [CrossRef]

84. Ringle, C.M.; Wende, S.; Will, A. SmartPLS 2.0. 2005. Available online: www.smartpls.de (accessed on 1 September 2019).

85. Fornell, C.; Larcker, D.F. Evaluating structural equation models with unobservable variables and measurement error. J. Mark. 1981, 18, 39-50. [CrossRef]

86. Garson, G.D. Path Analysis. Available online: http://www.statisticalassociates.com/pathanalysis.htm (accessed on 24 January 2019).

87. Yun, J.J.; Liu, Z. Micro-and macro-dynamics of open innovation with a quadruple-helix model. Sustainability 2019, 11, 3301. [CrossRef]

88. Trejo-Perea, M.; Rios Moreno, G.J.; Castañeda-Miranda, A.; Vargas-Vazquez, D.; Carrillo-Serrano, R.V.; Herrera-Ruiz, G. Development of a real-time energy monitoring platform user-friendly for buildings. Procedia Technol. 2013, 7, 238-247. [CrossRef]

89. Ehrhardt-Martinez, K.; Donnelly, K.A.; Laitner, J.A. Advanced Metering Initiatives and Residential Feedback Programs: A Meta-Review for Household Electricity-Saving Opportunities; American Council for an Energy-Efficient Economy: Washington, DC, USA, 2010.

90. Leng, G.S.; Lada, S.; Muhammad, M.Z.; Ibrahim, A.A.H.A.; Amboala, T. An exploration of social networking sites (SNS) adoption in Malaysia using Technology Acceptance Model (TAM), Theory of Planned Behavior (TPB) and Intrinsic Motivation. J. Internet Bank. Commer. 2011, 16, 1-27. Available online: http://www.icommercecentral.com/open-access/an-exploration-of-social-networking-sites-snsadoption-in-malaysia-using-technology-acceptance-model-tam-theory-of-planned-behavior-tpb-andintrinsic-motivation.php?aid=38251 (accessed on 1 September 2019).

91. Wilhite, H. Energy consumption as cultural practice: Implications for the theory and policy of sustainable energy use. In Cultures of Energy: Power, Practices, Technologies; Routledge: Abingdon, UK, 2013; pp. 60-72.

92. Wilhite, H.; Ling, R. Measured energy savings from a more informative energy bill. Energy Build. 1995, 22, 145-155. [CrossRef]

93. Mishra, D.; Akman, I.; Mishra, A. Theory of Reasoned Action application for green information technology acceptance. Comput. Hum. Behav. 2014, 36, 29-40. [CrossRef]

94. Paul, J.; Modi, A.; Patel, J. Predicting green product consumption using theory of planned behavior and reasoned action. J. Retail. Consum. Serv. 2016, 29, 123-134. [CrossRef]

95. Nie, H.; Vasseur, V.; Fan, Y.; Xu, J. Exploring reasons behind careful-use, energy-saving behaviours in residential sector based on the theory of planned behaviour: Evidence from Changchun, China. J. Clean. Prod. 2019, 230, 29-37. [CrossRef]

96. Judge, M.; Warren-Myers, G.; Paladino, A. Using the theory of planned behaviour to predict intentions to purchase sustainable housing. J. Clean. Prod. 2019, 215, 259-267. [CrossRef] 
97. Santos-Feliscuzo, L.T.; Himang, C.M. Library periodical indexing software evaluation using unified theory of acceptance and use of technology. Procedia Soc. Behav. Sci. 2011, 25, 104-114. [CrossRef]

98. Trappey, A.J.; Trappey, C.V.; Govindarajan, U.H.; Chuang, A.C.; Sun, J.J. A review of essential standards and patent landscapes for the Internet of Things: A key enabler for Industry 4.0. Adv. Eng. Inform. 2017, 33, 208-229. [CrossRef]

99. Bagheri, B.; Yang, S.; Kao, H.A.; Lee, J. Cyber-physical systems architecture for self-aware machines in Industry 4.0 environment. IFAC Pap. Line 2015, 48, 1622-1627. [CrossRef]

100. Rüßmann, M.; Lorenz, M.; Gerbert, P.; Waldner, M.; Justus, J.; Engel, P.; Harnisch, M. Industry 4.0: The Future Productivity and Growth in Manufacturing Industries. Boston Consult. Group 2015, 9, 54-89.

101. Pereira, T.; Barreto, L.; Amaral, A. Network and information security challenges within Industry 4.0 paradigm. Procedia Manuf. 2017, 13, 1253-1260. [CrossRef]

102. Henseler, J.; Ringle, C.; Sinkovics, R.R. The use of partial least squares path modeling in international marketing. New challenges to international marketing. Adv. Int. Mark. 2009, 20, 277-319.

103. Ashok, M.; Day, M.; Narula, R. Buyer (dis) satisfaction and process innovation: The case of information technology services provision. Ind. Mark. Manag. 2018, 68, 132-144. [CrossRef]

104. Pallant, J. SPSS Survival Manual: A Step by Step Guide to Data Analysis Using SPSS, 4th ed.; Open University Press/McGrawHill: Maidenhead, UK, 2010.

105. Hair, J.; Black, W.; Babin, B.; Anderson, R.; Tatham, R. Multivariate Data Analysis, 6th ed.; Pearson Prentice Hall: Uppersaddle River, NJ, USA, 2006.

106. Aldás-Manzano, J.; Lassala-Navarré, C.; Ruiz-Mafé, C.; Sanz-Blas, S. The role of consumer innovativeness and perceived risk in online banking usage. Int. J. Bank Mark. 2009, 27, 53-75. [CrossRef]

(C) 2020 by the authors. Licensee MDPI, Basel, Switzerland. This article is an open access article distributed under the terms and conditions of the Creative Commons Attribution (CC BY) license (http://creativecommons.org/licenses/by/4.0/). 